\title{
La rescisión o nulidad por falta de emplazamiento en el Código de Procedimiento Civil chileno
}

\author{
Felipe Gorigoitía Abbott*
}

\begin{abstract}
RESUMEN
El presente artículo analizará el incidente de rescisión (o nulidad) de lo obrado por falta de emplazamiento del art. 80 del Código de Procedimiento Civil, en especial en lo referente a sus presupuestos de procedencia y consecuencias. Se le caracterizará como un medio para dejar sin efecto juicios en los que no ba babido un efectivo emplazamiento, incluso en casos en los que no ha existido vicio alguno, que puede ser ejercido por cualquier persona que fue o ha debido ser parte en el proceso, aun cuando este ya se encuentre terminado.
\end{abstract}

Emplazamiento; rescisión; nulidad; rebeldía

\section{Rescission (or nullity) of proceedings due to the lack of summon}

\begin{abstract}
This article will analyze the incident of rescission (or nullity) of proceedings due to the lack of summon from article 80 of the Code of Civil Procedure, especially regarding its grounds and consequences. It will be characterized as a means to leave without effect proceedings in which there has not been an effective summon, even in cases where there has been no defect, that can be exercised by any person who was or should have been claimant in the process, including after said process has finished.
\end{abstract}

Summon; rescission; nullity; default judgment

* Licenciado en Ciencias Jurídicas, Universidad de Valparaíso, Chile. Doctor en Derecho, Universitat Pompeu Fabra, España. Profesor de Derecho Procesal, Universidad de Valparaíso, Chile. ORCID: https:// orcid.org/0000-0002-3842-9422 .Correo electrónico: felipe.gorigoitia@uv.cl .

Artículo recibido el 31.10.19 y aceptado para su publicación el 21.12.20. 


\section{INTRODUCCIÓN}

$\mathrm{E}$ 1 artículo 80 del Código de Procedimiento Civil (CPC) dispone que "Si al litigante rebelde no se le ha hecho saber en persona ninguna de las providencias libradas en el juicio, podrá pedir la rescisión de lo obrado, ofreciendo acreditar que, por un hecho que no le sea imputable, han dejado de llegar a sus manos las copias a que se refieren los artículos 40 y 44, o que ellas no son exactas en su parte substancial. Este derecho no podrá reclamarse sino dentro de cinco días, contados desde que aparezca o se acredite que el litigante tuvo conocimiento personal del juicio".

El incidente contemplado en el artículo transcrito permite al litigante rebelde pedir la rescisión de todo lo obrado cuando, por circunstancias ajenas a su responsabilidad, no ha llegado a enterarse de la existencia de un litigio. Es un incidente con características bastante especiales, por cuanto, como se verá, puede incoarse incluso una vez afinado un juicio y no requiere de un defecto procesal como presupuesto para su aplicación. Con clara inspiración en la legislación española, pero asumiendo ciertas particularidades ${ }^{1}$, la redacción del hoy artículo 80 (originalmente artículo 83) se debe a José Bernardo Lira. En más de un siglo, la disposición no ha sufrido alteraciones en su texto ${ }^{2}$.

La existencia de un mecanismo de este tipo es un contrapeso a la necesidad de todo sistema procesal civil de posibilitar el avance del proceso sin la comparecencia del sujeto pasivo de la pretensión. En especial, se hace necesario en los casos en los que son más severas las consecuencias de la rebeldía, como en aquellas situaciones en que puede entenderse como una aceptación de las pretensiones de la contraria (ficta confessio) y no como una resistencia a ella (ficta litis contestatio) $)^{3}$, como ocurre en el procedimiento ejecutivo o laboral, a los que resulta aplicable el art. 80.

El presente trabajo analizará dicho mecanismo procesal, a objeto de revisar su alcance y sus aspectos más relevantes. Se buscará demostrar que es un instrumento procesal indispensable en el sistema que debe servir para tutelar cualquier situación en la que un juicio pretenda afectar a quien no ha tenido una efectiva posibilidad de defenderse en él.

\section{NotificACIONES COMO PROTOCOLOS FALIBLES Y EL EMPLAZAMIENTO}

El diseño de un sistema de notificaciones es una constante tensión entre el derecho de defensa del demandado, que solo podrá ejercerse en la medida de que este sea efectivamente

\footnotetext{
${ }^{1}$ BiAnCHI, 1949, p. 186.

${ }^{2}$ A pesar de ser un incidente bastante recurrido en la práctica, nuestros manuales, incluso los más recientes, le prestan escasa atención, limitándose normalmente a reproducir sus exigencias (véase, por ejemplo, Pérez y Núñez, 2015, pp. 222-229; Bordalí en Bordalí, Cortés y Palomo, 2016, p. 393; y Romero, 2017 p.59). En la jurisprudencia, el panorama no es mucho mejor. Aunque hay un número significativo de sentencias de primera y segunda instancia, muy rara vez hay en ellas alguna reflexión que pase de la sola valoración de la prueba, en especial en casos de notificaciones en virtud del art. 44 CPC efectuadas en domicilios supuestamente equivocados.

${ }^{3}$ Orellana y Pérez, 2007, pp. 20 y ss.
} 
emplazado, y el derecho a la tutela judicial del demandante, que muchas veces puede quedar impedido de materializarse si es que no se logra notificar a su contraparte ${ }^{4}$. Un sistema que se preocupara solo del primero, procuraría que al menos la notificación de la primera resolución dictada fuese en persona, de manera de asegurarse que va a conocer la existencia de un juicio en su contra y podrá actuar en él. Por el contrario, un sistema que tienda a preocuparse exclusivamente del derecho del demandante creará formas alternativas de comunicaciones que supongan protocolos de actuación menos fiables y más fáciles de realizar, asumiendo que en varios casos el notificado puede que no logre enterarse efectivamente de lo comunicado.

Ningún sistema de comunicaciones puede depender del efectivo conocimiento de la resolución de parte del notificado para la eficacia de todas sus notificaciones. Asumiendo esto, es que se conforma con la presunción de conocimiento a partir del cumplimiento de ciertas formalidades legales. Furquet explica que esto está respaldado "por la creencia de que la presunción de conocimiento legal resulta acertada la mayoría de las veces, entre otras razones, porque las normas están redactadas con la suficiente sensatez como para permitir entender que normalmente el cumplimiento de las formalidades legales va a situar el acto de comunicación lo bastante cerca del destinatario como para conseguir que este acabe conociendo su contenido" 5 .

En este entendido, nuestro Código de Procedimiento Civil opta por un sistema que pretende resguardar de manera razonablemente equilibrada ambos derechos. Si bien dispone que la primera notificación a las partes o a las personas a quienes hayan de afectar sus resultados, salvo al demandante, ha de hacerse de forma personal (art. 40), contempla la posibilidad de que esta sea reemplazada, previa autorización judicial, por una notificación por cédula en el lugar que se certifique por el ministro de fe respectivo como su morada o lugar donde ejerce habitualmente su industria, profesión o empleo, siempre que se constate también que el notificado se encuentra en el lugar del juicio (art. 44). Además, el ministro de fe tiene el deber de enviar una carta certificada al domicilio de la notificación, que dé noticia de que se ha practicado la notificación y los datos del litigio (art. 46).

A veces, a pesar de las gestiones del actor, no se logra determinar el domicilio del demandado o, peor aún, ni siquiera se puede precisar quiénes son las personas en contra de quienes se debe dirigir la acción. En estas situaciones el CPC permite la notificación por avisos en un diario del lugar en donde se sigue el juicio y en el Diario Oficial, en este último caso en un día de fecha $1^{\circ}$ o 15 (art. 54), lo que es una clara opción a favor de la tutela judicial del demandante, en detrimento del derecho a defensa del demandado. Es una forma de comunicación muy poco eficiente ${ }^{6}$, ya que es improbable que efectivamente se logre poner en conocimiento del notificado aquello que se publica.

\footnotetext{
${ }^{4}$ Yelamos, 2006, p. 353.

${ }^{5}$ Furquet, 2005, p. 237.

${ }^{6}$ Furquet, 2005, p. 200.
} 
En casos especiales, se ha privilegiado aún más el derecho a la tutela del demandante, al establecer formas de notificación que priorizan la eficacia y celeridad del proceso, por sobre las efectivas probabilidades de conocimiento del demandado. Es lo que ocurre, por ejemplo, en los procedimientos regidos por la Ley 18.101, sobre arrendamiento de predios urbanos, en el que se presume de pleno derecho como domicilio del demandado el del inmueble arrendado a efectos de la notificación del art. 44 CPC (art. $8^{\circ}$, regla segunda); en materia de cobro de impuesto territorial, en el que la demanda de cobro se notifica por cédula en el inmueble objeto del impuesto, aunque sea un sitio eriazo, como ha ocurrido en algún caso (art. 171, inciso $4^{\circ}$, del Código Tributario); o para la notificación del protesto de cheque que se puede realizar por cédula en el domicilio del girador, incluso si este ya no vive ahí (art. 41 DFL 707).

Todo sistema de comunicaciones procesales tiene márgenes de error, que, en este caso, pueden tener como consecuencia dejar en la más absoluta indefensión al demandado. Esto se puede producir principalmente por tres situaciones:

- Una notificación irregular realizada incumpliendo requisitos legales, como puede ser una efectuada en un domicilio equivocado o a una persona que no se encuentra en el lugar del juicio;

- Una notificación falsa, que es aquella que no se ha realizado o que, habiéndose efectuado, no se ha hecho como se da cuenta por el ministro de fe;

- Notificación ineficaz, practicada cumpliendo con los requisitos legales, pero que no ha logrado comunicar lo que debía a quien correspondía.

Los dos primeros casos son bien resueltos por las normas generales de nulidad procesal, cuestión que no obsta a que se puede impetrar la rescisión del art. 80. En los términos del artículo $83 \mathrm{CPC}$, son actos viciosos que pueden llegar a irrogar a los notificados un perjuicio reparable solo por la declaración de nulidad.

El problema surge para la tercera hipótesis. En ella la nulidad procesal del artículo 83 no tiene cabida, porque no hay vicio alguno. Para estos casos es que se vuelve relevante la rescisión del artículo 80 CPC, que precisamente busca resolver esta situación con una disposición que busca evitar que todos los riesgos del sistema recaigan en el litigante rebelde que no ha tenido siquiera la posibilidad de conocer la existencia del juicio, evitando que se pueda dictar una sentencia sin previo y eficaz emplazamiento al demandado.

\section{Presupuestos DE APLICACIÓN}

\section{Oportunidad}

Aunque no hay norma que expresamente lo contemple, no cabe duda alguna ni en el ámbito doctrinal ni en el jurisprudencial en cuanto a que la rescisión por falta de emplazamiento puede ser pedida en cualquier momento del juicio, incluso una vez 
terminado este por sentencia firme. Desde el punto de vista normativo, y aunque antes hubo alguna discusión acerca de esto ${ }^{7}$, la cuestión se reputa zanjada desde la ley 7.706 , de 5 de febrero de 1944, que, si bien no introdujo cambios al artículo 80, incluyó en el artículo 234 CPC un inciso final que contempla la posibilidad de pedir, en la etapa de cumplimiento incidental de la sentencia ${ }^{8}$.

A partir de esta característica, se ha elaborado la noción de la cosa juzgada aparente, sosteniendo que, en los casos en los que no ha habido un emplazamiento real, más que un proceso hubo tan solo una apariencia de tal. En términos muy gráficos, Santa Cruz explica que "Omitido el emplazamiento del reo, no se habrá formado respecto de él la relación procesal y todo el proceso y la sentencia estarán privados de ese vínculo jurídico que es el antecedente de donde pueden derivar su autoridad respecto del demandado. Podrá dictarse la sentencia definitiva, podrán quedar 'aparentemente' firme o ejecutoriada; pero nunca podrá adquirir válidamente ese carácter, nunca podrá tener autoridad de cosa juzgada respecto de un demandado que no ha sido emplazado, que no ha sido citado al proceso o a quien no se ha dado la oportunidad mínima de defensa" ${ }^{\text {. }}$.

Más allá de cómo se califique doctrinariamente, el incidente en cuestión constituye la vía casi exclusiva de anulación de juicios ya terminados, en atención a que las incidencias deben plantearse in limine litis ${ }^{10}$; que no existe la posibilidad de iniciar nuevos procesos para anular lo ocurrido en otros ${ }^{11}$; y que la revisión de sentencias firmes civiles es estadísticamente irrelevante ${ }^{12}$. Esta característica debe promover un entendimiento amplio al momento de interpretar su legitimación activa y los supuestos de hecho de procedencia del incidente. Por mucho que se quiera resguardar la "santidad" de la cosa juzgada, ella no puede afectar a quien no ha tenido una auténtica posibilidad de defenderse. La seguridad jurídica no se puede construir a partir de supuestos que niegan el derecho al debido proceso.

\section{Legitimado para incoar la rescisión}

El legitimado para incoar la rescisión por falta de emplazamiento es, según el art. 80, el "litigante rebelde". El Código de Procedimiento Civil maneja la denominación de rebeldía con algo de vaguedad. En general, denomina rebelde simplemente a la parte que no ha realizado una determinada actuación procesal dentro del plazo que la ley confiere

\footnotetext{
${ }^{7}$ BIANCHI, 1949, p. 189 y ss.

8 Salas, 2000, p. 100; Pereira, 2004, p. 130; Carrasco, 2010, p. 91.

9 Salas, 2000, p. 101; Hoyos, 2001, p. 247; Romero, 2004, p. 36; Pereira, 2004, p. 128; Carrasco, 2010 , p. 92.

${ }^{10}$ Salas, 2000, p. 97.

${ }^{11}$ Carrasco, 2015, pp. 684 y ss.

${ }^{12}$ En los últimos quince años, salvo error u omisión, se han acogido solo cuatro acciones de revisión en materia civil, dos fundadas en cosa juzgada no alegada oportunamente (rol 3.284-2004, de 2 de mayo de 2006; y rol 28.606-2016, de 27 de octubre de 2016) y otras dos en falsedades documentales (rol 4.7632013, de 2 de diciembre de 2013; y rol 820-2015, de 16 de enero de 2017).
} 
(por ejemplo, en los artículos 78, 79, 248, entre otros) ${ }^{13}$. Dicha acepción, sin embargo, no es la que se emplea en esta incidencia, pues no basta con no haber realizado alguna actuación, sino que se requiere, además, no haberse apersonado juicio ${ }^{14}$.

Considerando lo anterior, el natural llamado a promover una incidencia de esta especie es el demandado que no ha comparecido al juicio. No cabe duda que esto es así. La cuestión pasa por revisar si alguien más, otro "litigante", puede eventualmente encontrarse legitimado en este sentido. Nuestra doctrina circunscribe la legitimación al demandado ${ }^{15}$, pero sin profundizar.

Un análisis más detenido requiere plantearse tres cuestiones: (1) quién debe reputarse como litigante; (2) si terceros que no han comparecido en el juicio pueden recurrir a este mecanismo; (3) si, en algún caso, puede el mismo demandante promover una incidencia de esta especie.

(1) Debe reputarse como litigante no solo a quien ostenta propiamente la posición de demandado, sino también a quien es sujeto pasivo de medidas prejudiciales o de gestiones preparatorias de la vía ejecutiva y que deben ser notificados personalmente de ellas. Así, por ejemplo, al que se le da por confeso de conformidad al artículo 435 del Código de Procedimiento Civil puede pedir la rescisión en caso de no haberse enterado de la citación por un hecho no imputable a él.

La interpretación armónica de los artículos 40 y 80 CPC y la finalidad de la institución, necesariamente lleva a la conclusión que, en definitiva, se ha de entender a efectos de esta incidencia como litigante a cualquier persona que, por exigencia del art. 40 , deba ser notificada personalmente de la primera resolución dictada en el juicio.

(2) La cuestión acerca de si terceros pueden hacer uso de esta incidencia sería menos clara. Esto podría resultar relevante, por ejemplo, en el caso de existir un litisconsorcio pasivo necesario que no se haya respetado. Una salida fácil es descartar tal alternativa, sosteniendo que los terceros que comparecen como tales deben respetar todo lo obrado en él, circunstancia que supondría una auténtica renuncia a pedir cualquier tipo de nulidad, por disposición de los artículos 22 y 23 CPC. Sin embargo, siguiendo a Tavolari, este argumento puede ser rebatido considerando que no parece acertado estimar que el tercero, por el solo hecho de pretender ser parte, renuncia a la posibilidad de reclamar la nulidad. Las disposiciones de los artículos 23 y, en especial, 22 del Código de Procedimiento Civil buscan evitar que se pueda retrotraer el procedimiento a etapas ya cerradas y no evitar que el tercero pueda cuestionar la validez de actuaciones anteriores ${ }^{16}$.

Además de lo anterior, debe tenerse en cuenta que conforme con el art. 40 CPC, deben ser notificadas personalmente de la primera resolución dictada en el juicio no solo a las partes, sino "las personas a las que haya de afectar sus resultados", hipótesis

\footnotetext{
13 Carrasco, 2010, p. 35.

${ }^{14}$ Carrasco, 2010, p. 89.

15 Salas, 2000, p. 97; Carrasco, 2010, p. 332.

16 Tavolari, 2004, p. 274.
} 
en la que caben los terceros a los que les podría llegar a interesar la anulación del fallo por este motivo.

Por último, es admisible tener presente que el tercero tiene la posibilidad de alegar que la sentencia no le empece, en caso de que se pida el cumplimiento en contra de ella (artículo 234, inciso segundo, CPC). Si es que el tercero puede reclamar por esta vía es porque se está pretendiendo hacerle oponible un juicio en el que no ha sido parte, pero en el que ha debido serlo. La existencia de esta disposición debe llevar a la conclusión que el tercero debe poder hacer ejercicio del artículo 80 CPC por dos motivos:

- Resultaría absurdo que en caso de enterarse de la existencia de un litigio en el que puede tener interés deba esperar hasta el fin de este para pedir la inoponibilidad en vez de buscar defenderse antes;

- La mencionada disposición está admitiendo que existe la posibilidad que una sentencia afecte a un tercero que no ha sido parte y lo protege, pero en un ámbito muy restringido, cual es que se pida el cumplimiento de una sentencia en su contra. Si es que no se acepta la posibilidad de que emplee el mecanismo del artículo 80, entonces si la sentencia fuese meramente declarativa no tendría medio para defenderse (podría ser el caso, por ejemplo, de un contratante que no fue emplazado en un juicio de nulidad del contrato que ha suscrito).

Aunque no es un tema pacífico, la jurisprudencia ha reconocido esta posibilidad. En un caso en el que el Fisco de Chile comparece como tercero pidiendo la anulación de la sentencia firme por falta de emplazamiento en una causa en la que no ha sido demandado, la Corte Suprema declaró que: "Y aun cuando el Fisco no hubiese tenido el carácter de litigante, es lo cierto que tratándose de un vicio que anula el proceso por no baberse seguido contra legítimo contradictor, por los fundamentos consignados en la resolución del juez a quo, ha resultado suficiente su sola verificación para que el juez pudiera declarar la nulidad de todo lo obrado" ${ }^{17}$. Incluso por la vía del recurso de protección se ha reconocido la posibilidad de que un tercero comparezca pidiendo la nulidad por falta de emplazamiento en casos en los que no ha sido parte debiendo serlo ${ }^{18}$.

(3) Extender la legitimación al demandante resulta difícil de imaginar, debido a que, casi por definición, quien demanda debe saber de la existencia del juicio. En todo caso, sería posible concebir la situación cuando quien ha actuado por otro no tenía las facultades para hacerlo, como podría ser quien obra con un mandato revocado o simplemente sin mandato.

En síntesis, debe reconocerse la calidad de litigante rebelde a cualquier persona que sea parte en un asunto judicial y no ha comparecido en él, pero también a quien no

${ }^{17}$ Corte Suprema, 3.7.2007, rol No 1.111-1997, el énfasis ha sido agregado. En el mismo sentido,

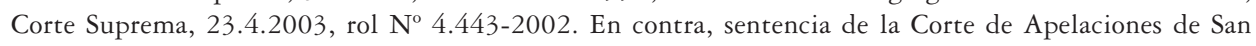
Miguel, 24.7.2014, rol No 115-2014.

${ }^{18}$ Corte de Apelaciones Valdivia, 29.1.2004, rol 14.899-2003. 
ha sido emplazado por no figurar como litigante en él, a pesar de que le puedan afectar directamente los resultados del juicio.

\section{Casos de procedencia}

\subsection{Las hipótesis indicadas en el art. 80 son solo ejemplares}

La literalidad del artículo 80 haría suponer que la incidencia en cuestión puede incoarse solo en dos hipótesis muy precisas, ambas relacionadas con la notificación personal, y en especial, con la subsidiaria del artículo 44 CPC. En concreto, se autoriza cuando (1) las copias de lo que deben ser entregadas no han llegado al poder del notificado por hechos que no le son imputables, o bien (2) cuando estas no son iguales en lo sustancial a lo que debe ser notificado. De las dos hipótesis literales, sin duda, la primera es por mucho la más frecuente. Fundada en ella es que se pueden reclamar situaciones como la notificación que se ha realizado en un domicilio que no corresponde, la practicada a una persona que se encontraba fuera del lugar del juicio, la situación de una notificación falsa o una comunicación simplemente omitida.

Sin embargo, la jurisprudencia y la doctrina hace bastante tiempo han remarcado que las hipótesis enunciadas en la disposición en estudio son solamente ejemplares, y que el incidente en cuestión procede en cualquier situación de falta de emplazamiento o de emplazamiento defectuoso que no resulte imputable a la parte ${ }^{19}$. Así, es factible la posibilidad de pedir, por ejemplo, la anulación de una notificación por avisos que no se realice conforme a su estatuto legal ${ }^{20}$ o cuando la información proporcionada por el receptor judicial al entregar las copias lleva a creer al demandado que se trata de un asunto de una especie diversa a la que es ${ }^{21}$.

\subsection{No se requiere de un defecto procesal para que opere}

Aunque no se le ha dado demasiada atención al punto, buena parte de la doctrina parece entender que para que se puede impetrar un incidente en virtud del art. 80 CPC es necesario que la notificación sea defectuosa. Salas, por ejemplo, afirma que se aplica, fuera de sus hipótesis expresas, en los casos en que "se haya omitido el emplazamiento del demandado rebelde o tal trámite sea defectuoso"22. En la misma línea, Carrasco sostiene que se "aplica para todas aquellas notificaciones, citaciones y emplazamientos que no se hubieran practicado con arreglo a lo dispuesto en la propia ley" ${ }^{23}$.

\footnotetext{
${ }^{19}$ Santa Cruz, 1936, p. 63; Salas, 2000, p. 100; Carrasco, 2010, p. 89.

${ }^{20}$ Corte de Apelaciones de Chillán, 11.5.2004, rol No 27.332-2003. En contra, Corte de Apelaciones de Santiago, 15.04.2011, rol 5.486-2011.

${ }^{21}$ Corte de Apelaciones de Santiago, 3.8.2016, rol No 5.872-2016.

22 Salas, 2000, p. 100.

${ }^{23}$ Carrasco, 2010, p. 89. También: Colombo, 1997, p. 504.
} 
Esta interpretación no parece correcta. A diferencia de lo que ocurre con el estatuto general de la nulidad procesal, que exige la existencia de un acto defectuoso, para este caso no se requiere de tal. Basta con que la circunstancia que haya impedido el conocimiento del juicio -y, por tanto, el ejercicio del derecho de defensa- no sea imputable a la parte. Así se desprende del tenor literal del mencionado artículo. De esta manera, podría ser susceptible de ser anulado un proceso en el que las copias que exige el artículo 44 CPC no lleguen al poder del notificado por hechos fortuitos, como puede ser que se desprendan por acción de la naturaleza o el simple olvido de la persona (distinta del demandado) que la recibe. Lo relevante es que aquella circunstancia que haya impedido el conocimiento no sea atribuible a su negligencia. Por ello es que Bianchi afirma que procede respecto de "una notificación efectuada con arreglo a todas las exigencias de la ley" ${ }^{24}$ y Otero la reconoce como un caso excepcional de nulidad sin vicio ${ }^{25}$.

La historia del artículo 80 abona la tesis de que no requiere de un defecto alguno. Es un mecanismo procesal que hace prevalecer en un caso extremo de indefensión la justicia por sobre la seguridad jurídica. Aunque con modificaciones, su inspiración más inmediata fue la de la audiencia al litigante rebelde de la Ley de Enjuiciamiento Civil Española de 1855 y su modificación de 1880, que se da en hipótesis en las que se presume un emplazamiento válido, por circunstancias no imputables al rebelde ${ }^{26}$.

El que no se requiera de un vicio procesal es lo que ha llevado al CPC a emplear, al igual que en el incidente por fuerza mayor, el término de rescisión. Aunque se pueda tomar como una impropiedad ${ }^{27}$ pues poco tiene que ver con el uso de la palabra que se da en el derecho civil, siguiendo a la LEC española, se ha usado una expresión que quiere hacer una diferenciación con la nulidad en el hecho de no exigir la existencia de un defecto procesal ${ }^{28}$, sino un acto válido con una lesión o perjuicio sobrevenido ${ }^{29}$.

La existencia de vías anulatorias para casos en los que hay emplazamientos formalmente correctos, pero ineficaces, es común en el derecho comparado. En el proceso español vigente encontramos la figura de "la rescisión de sentencia firme a instancias del rebelde” (artículo 501 de la Ley de Enjuiciamiento Civil de 2000) que contempla, básicamente, tres causales de procedencia: la fuerza mayor que ha impedido al rebelde comparecer a pesar de conocer del juicio; el desconocimiento de la demanda y del pleito por no haber llegado la notificación por cédula al demandado por causas que no le son imputables; y, en el caso de la notificación por edictos, el desconocimiento debido a no

${ }^{24}$ BIANCHI, 1949, p. 180. El art. 776 de la LEC 1881 decía "Se prestará audiencia contra la sentencia dictada en su rebeldía al demandado que hubiere sido emplazado por cédula entregada a sus parientes, familiares, criados o vecinos, si concurrieren las dos circunstancias siguientes: $1 .^{\circ}$ Que la pida precisamente dentro de ocho meses, contados desde la fecha de la publicación de la sentencia en el «Boletín Oficial» de la provincia. 2. ${ }^{\circ}$ Que acredite cumplidamente que una causa no imputable al mismo ha impedido que la cédula de emplazamiento le haya sido entregada”.

25 Otero, 2009, p. 62.

${ }^{26}$ BIANCHI, 1949, p. 181.

27 Tavolari, 2004, p. 271; Figueroa y Morgado, 2013, p. 275.

${ }^{28}$ Carlos, 1975 , pp. 143 y ss.

${ }^{29}$ Broceño, 2014, p. 243. 
encontrarse en el lugar en donde se siguió el proceso y cualquier otro lugar en donde se hubiese publicado el aviso. Resulta interesante constatar que en este sistema la rescisión no anula el juicio completamente, sino que da lugar a un juicio abreviado en el que se revisa lo decidido en el procedimiento anterior, con la posibilidad de que el demandado rebelde haga valer sus pretensiones y rinda prueba ${ }^{30}$.

Este mecanismo se da en el contexto de otras figuras similares existentes en el derecho europeo continental que pretenden reparar la indefensión causada por una rebeldía involuntaria sin defectos procesales, como la alemana o italiana ${ }^{31}$. En el caso alemán, se pueden reponer las actuaciones a un estado anterior, incluso si ha habido sentencia, siempre que la parte se haya visto impedida de actuar sin culpa propia al respecto, aunque no intervenga propiamente una fuerza mayor ${ }^{32}$. En el italiano, por su parte, se contempla algo parecido para aquellos casos en los que la rebeldía se ha originado en el desconocimiento del proceso por una causa que no le resulta imputable ${ }^{33}$.

En el derecho anglosajón también se contempla la posibilidad de dejar sin efecto una sentencia dictada en rebeldía (default judgement). De conformidad con las Federal Rules of Civil Procedure, de Estados Unidos de Norteamérica, una sentencia y el procedimiento que le ha precedido pueden ser dejados sin efecto cuando la incomparecencia ha sido causada por error, inadvertencia, sorpresa o negligencia excusable de la afectada (regla 60 b), siempre que demuestre haber actuado de buena fe y solicite la anulación en un plazo razonable ${ }^{34}$.

Este brevísimo panorama viene a mostrar que la existencia de una vía rescisoria que permita dejar sin efecto incomparecencias originadas en situaciones no imputables al rebelde es una exigencia de todo sistema procesal que pretenda cumplir los estándares del debido proceso. Un procedimiento en el que todo el riesgo de falibilidad de los protocolos de notificación queden entregados al notificado, sin posibilidad de revisión posterior, atenta contra cualquier noción del derecho de defensa que no se quede solo en lo formal.

\subsection{Necesidad de perjuicio}

Nada de lo explicado excluye la necesidad de un perjuicio reparable solo por la nulidad, que no es más que la expresión del principio de trascendencia que inspira todo el sistema de la nulidad procesal. Si bien no es necesario invocar o acreditar las defensas concretas que se debieron hacer, pues la sola situación de no haberse enterado de la

${ }^{30}$ Ramos, F., 2008, p. 1.517.

31 Arts. 296 del Códice de procedura civil y 233 ZPO. Sobre ambas véase D’ AdAMO, A., Contributo allo studio della contumacia nel processo civile, Giuffrè, Milano, 2012, pp. 107 y ss. y 307 y ss.

32 D'Adamo, A., 2012, pp. 307 y ss.; Hess, B. y Jauring, O., 209 y ss.

${ }_{33}$ D'Adamo, A., 2012, pp. 107 y ss. Contributo allo studio della contumacia nel processo civile, Giuffrè, Milano, 2012, pp. 107 y ss.

${ }^{34}$ Bresnan, P. y Cornelio, J., 1981, pp. 970 y ss. 
existencia del juicio hace presumir la existencia de un perjuicio de suficiente entidad ${ }^{35}$, igualmente no procederá esta alegación si es que los hechos no le producen afectación alguna, como en el caso de quien invoca la rescisión o nulidad y en subsidio contesta u opone excepciones dentro de plazo $^{36}$.

Ese perjuicio ha de ser claramente identificado en la misma solicitud de nulidad, en especial en los casos en que el incidente es promovido por una persona que no es parte, pero postula que debe serlo, en donde la sola presunción recién mencionada no basta. Ella sí requerirá una explicación acerca de por qué debe ser considerada en el juicio, qué pretensiones puede hacer valer y cómo le puede afectar directamente la sentencia.

El perjuicio, además, deberá ser reparable solo mediante la declaración de nulidad, lo que permite descartar cualquier afectación que pueda ser reparada por medio de la subsanación del defecto procesal. En materia de notificaciones, esto es poco frecuente, pero, nuevamente, si la alega un tercero, no solo deberá explicar por qué debe ser parte, sino el motivo por el cual es indispensable anular para que sus derechos sean respetados, sin que baste la aceptación de su comparecencia en el estado en que se encuentra el juicio.

\section{Plazo para incoar la incidencia}

Si bien la oportunidad para pedir la rescisión es bastante amplia, el plazo para solicitarlo es breve. En efecto, una vez conocida la existencia del juicio, el plazo para promover la incidencia es de solo cinco días, contados desde que aparezca o se acredite el conocimiento personal de él.

El primer problema que plantea esta exigencia guarda relación con qué debe entenderse por "conocimiento personal del juicio" a efectos de esta disposición. Si bien gran número de incidentes de este tipo se desestiman por la imposibilidad de acreditar esta exigencia, no hay, de nuevo, mayor análisis del punto.

Es claro que la exigencia se cumple solo en la medida en que el mismo litigante rebelde ha tenido noticia real de la existencia del proceso cuya rescisión pide. No basta, en ese sentido, la sola notificación para ello, si es que ella no ha permitido efectivamente acceder a la información requerida. La cuestión surge en relación con qué es de lo que debe imponerse, si de la sola existencia del litigio o de su contenido. Figueroa y Morgado lo entienden de la primera manera, sosteniendo que basta que exista en el incidentista "conciencia del juicio en su contra" ${ }^{37}$. Urrutia, por el contrario, postula que es necesario que este "haya visto y leído la demanda" 38 . Debido al tenor de la disposición y para evitar que la oportunidad quede en manos del mismo incidentista, la primera alternativa parece más acertada, aunque el plazo se vuelve algo breve, pues dentro de él deberá no

\footnotetext{
35 Corte de Apelaciones de Concepción, 9.7.2004, rol N 3.207-2003.

${ }^{36}$ Corte de Apelaciones de Santiago, 18.8.2016, rol No 8.664-2016.

${ }^{37}$ Figueroa y Morgado, 2013, p. 276.

38 URrutia, 1928, p. 167.
} 
solo interiorizarse del contenido del juicio, sino también procurar la asistencia letrada necesaria para reclamar la nulidad.

El conocimiento es uno de los puntos más difíciles desde la perspectiva de la prueba, pues impone una doble carga al incidentista:

(1) Por aplicación del artículo 427 del Código de Procedimiento Civil, se debe presumir que se ha producido el conocimiento con la notificación, por lo que se deberá demostrar los hechos que la han transformado en una comunicación ineficaz ${ }^{39}$. Si se alega un defecto procesal (como la notificación en un domicilio errado), será carga del incidentista rendir prueba suficiente para destruir la presunción legal de veracidad de lo atestado por el ministro de fe. La jurisprudencia en esto es particularmente exigente. En un fallo reciente, la I. Corte de Apelaciones de Antofagasta sostuvo "frente al atestado de un ministro de fe, como lo es la Receptora Judicial, se requiere prueba cierta y comprobada para desvanecer sus afirmaciones" ${ }^{40}$. Por su parte, si es que lo que se reclama es la existencia de una circunstancia ajena a la regularidad de la notificación que le ha privado de conocimiento, el afectado deberá acreditarla de manera tal que permita convencer al tribunal que los protocolos de seguridad establecidos en la regulación procesal, para el caso concreto, no han sido eficaces.

(2). Además, deberá acreditarse la fecha de real conocimiento del juicio, sea que este se origine en una actuación procesal (como podría ser otra notificación o un embargo) o extraprocesal (como el aviso de un tercero). La prueba debe hacerse cargo no solo de demostrar el hecho revelador de la existencia del juicio, sino también de excluir la posibilidad razonable de haber conocido de este con anterioridad.

El efecto de no proponer el incidente dentro del plazo de cinco días es la convalidación del defecto, lo que supone la aceptación de la indefensión causada ${ }^{41}$. Parece dudoso si es que la realización de cualquier actuación previa a la alegación de rescisión produce el mismo efecto. Al exigir solo un plazo el art. 80 , se ha entendido que actuaciones previas no necesariamente acarrean la convalidación del defecto ${ }^{42}$. Sin embargo, esto tiene una aplicación muy restringida, básicamente a actuaciones de mero trámite, como el otorgamiento de un mandato judicial o la solicitud de copias. La realización de actuaciones más sustanciales como contestar la demanda u oponer recursos serán de por sí muestras de que no ha existido perjuicio o de que se está renunciando a pedir la rescisión por esta vía.

\footnotetext{
39 Corte de Apelaciones de Chillán, 6.8.2013, rol No 260-2013.

${ }^{40}$ Corte de Apelaciones de Antofagasta, 6.6.2019, rol 407-2019.

41 Tavolari, 2004, p. 271.

42 Urrutia, 1928, p. 62; Carrasco, 2010, p. 93.
} 


\section{TRAMitACióN Y CONSECUENCIAS DE LA RESCISIÓN}

\section{Su tramitación es incidental}

No se han levantado mayores cuestiones acerca del carácter incidental del procedimiento que se viene estudiando, probablemente porque el mismo CPC, en su artículo 81 , le llama incidente. Como tal, es necesario recibirlo a prueba, en caso de haber controversia acerca de los hechos en que se funda ${ }^{43}$.

Se ha estimado que la resolución que lo falla es una sentencia interlocutoria y, por tanto, apelable ${ }^{44}$, conforme con el artículo 187 CPC, pero no susceptible de casación en la forma ni en el fondo (en el caso de la sentencia de segunda instancia), por no poner término al juicio ni impedir su prosecución ${ }^{45}$. Por los mismos motivos, no procede el recurso de queja, aunque excepcionalmente el conocimiento de este pueda generar alguna anulación de oficio de la Corte Suprema ${ }^{46}$.

Debido a las desconfianzas que suponía una alegación de esta especie, se estableció en el hoy art. 81 CPC, que este incidente no suspenderá la marcha del juicio ${ }^{47}$. Llama la atención cómo, a pesar de la disposición expresa, muchos tribunales tienen la asentada práctica de suspender su tramitación mientras se tramita ${ }^{48}$.

\section{Consecuencias de la rescisión}

La consecuencia de acogerse la alegación del litigante rebelde es la ineficacia de "lo obrado en el juicio". En este sentido, los efectos de acogerse no son distintos a los de la nulidad. Aunque se suele decir que es la anulación de todo lo obrado, eso no es exacto. Primero, porque en realidad se anula todo lo obrado a contar de la notificación de la primera gestión, quedando a salvo lo actuado antes de ella. Esto tiene el efecto práctico de que no es necesario, por ejemplo, volver a presentar la demanda. Además, y por aplicación del principio de conservación ${ }^{49}$, igualmente deben mantener valor las actuaciones procesales posteriores que no guarden relación directa con lo ocurrido con el demandado, como podrían ser los mandatos conferidos o eventuales conciliaciones o avenimientos con otras partes, en la medida que no afecten los derechos del rebelde restituido.

Adicionalmente, se producirán dos consecuencias:

\footnotetext{
43 Corte de Apelaciones de Rancagua, 15.4.2020, rol 376-2020.

${ }^{44}$ Corte de Apelaciones de Talca, 13.07.2018, rol 978-2018.

${ }^{45}$ Corte Suprema, 17.10.19, rol 12.139-2019; 24.10.2019, rol 24.165-2019, respectivamente, por nombrar solo las más recientes.

46 Corte Suprema, 30.04.2020, rol 29.322-2019.

${ }^{47}$ Bianchi, 1949, p. 181.

48 Carrasco, 2010, p. 93.

49 Gorigoitía, 2013, p. 149.
} 
- Operará la figura del inciso segundo del art. 55 CPC. Se tendrá por notificado de la primera resolución del juicio a quien ha promovido la rescisión, entendiéndosele de esta forma emplazado ${ }^{50}$.

- En caso de haber existido sentencia definitiva, el juez que conoció del asunto quedará inhabilitado para seguir conociendo de él, por aplicación del art. 195, No 8 del Código Orgánico de Tribunales.

\section{RELACIÓN CON FIGURAS AFINES}

\section{Incidente del artículo 83}

¿Puede un asunto ser, a la vez, causal de nulidad por el artículo 83 y por el artículo 80 ? La respuesta es afirmativa. Cualquier nulidad procesal que se reclame durante el juicio y que suponga un defecto procesal en el emplazamiento que ha impedido el conocimiento de él podrá asilarse en ambas disposiciones, volviéndose, en realidad, casi irrelevante si se resuelve por uno u otro, por cuanto el plazo es prácticamente el mismo.

Cuando se vuelve realmente importante la incidencia del artículo 80 es en las dos hipótesis en las que se puede exceder la nulidad del artículo 83: cuando se reclama una vez terminado el juicio y cuando se pide anulación sin que exista un defecto procesal.

\section{Rescisión por fuerza mayor}

La rescisión por fuerza mayor del artículo 79 comparte algunas características con la rescisión por falta de emplazamiento, por cuanto tampoco requiere de un defecto procesal que haya afectado a la actuación que se busca anular. Se podría afirmar que un hecho no imputable a la parte constituye, desde su perspectiva, una fuerza mayor. En este sentido, la hipótesis del artículo 80 estaría comprendida en la del artículo 79. El hecho de que este último tenga un plazo más largo para pedirlo hace que sea más recurrido.

Si bien no tiene mucha aplicación práctica, la rescisión por fuerza mayor es una manera bastante útil de remediar la rebeldía para actos procesales concretos para litigantes que no han podido realizar o comparecer a una actuación o diligencia por hechos involuntarios ${ }^{51}$. Su ámbito de aplicación se puede ver incluso más extendido para el caso en el que se estimase que para el art. 80 se requiere de un defecto procesal, ya que en este caso no hay duda que este no es necesario, pudiendo rescindirse cualquier actuación, aun cuando no esté viciada 52 .

\footnotetext{
${ }^{50}$ Carrasco, 2010, p. 90.

51 Carrasco, 2010, p. 87.

52 Salas, 2000, p. 100; Carrasco, 2010, p. 86.
} 


\section{LA RESCISIÓN POR FALTA DE EMPLAZAMIENTO en el Proyecto de CPC}

El Proyecto de Código Procesal Civil (PCPC) ${ }^{53}$ en su artículo 116 propone lo siguiente: "Inexistencia. La constatación de la inexistencia de los actos verificados, como ocurre con los practicados por o ante un órgano que no ejerza jurisdicción, se verificará, en cualquier tiempo, y sin más condiciones que la de citar previamente a los interesados. Excepcionalmente, en caso de falta de notificación de la demanda al demandado, dicha declaración deberá solicitarse dentro de los diez días siguientes desde que aparezca o se acredite que tuvo conocimiento personal del juicio”.

Lo propuesto tiene solo una ventaja en relación con lo existente, que es relativamente menor: aumenta el plazo para promover la incidencia, de cinco a diez días. En el resto, es más restrictivo o mantiene dificultades ya existentes.

El PCPC restringe la incidencia a los casos de "falta de notificación al demandado". Aun entendiendo que la falta de notificación debe hacer referencia a la omisión de una notificación hecha de conformidad a la ley, desaparece la hipótesis relativa al hecho de que la notificación no llegue al poder del demandado por causas que no le resulten imputables. Una restricción de esta especie excluye situaciones en las que formalmente la notificación fue realizada, pero en las que el demandado, por hechos no imputables a él, no ha llegado a tener conocimiento efectivo del juicio. Esto es particularmente difícil cuando, al mismo tiempo, se rebajan los estándares de las notificaciones ${ }^{54}$.

Además, se mantienen dos dificultades actuales. La primera es que deja como único legitimado al demandado, excluyendo toda posibilidad de que la falta de emplazamiento se transforme en una manera de control de casos de litisconsorcio necesario o, en general, en los que un tercero debió ser emplazado. Es efectivo que los terceros tienen el derecho a alegar la inoponibilidad del fallo, pero eso solo lo podrá hacer en la medida en que se intente una ejecución en su contra, lo que resulta insuficiente. La segunda dificultad tiene que ver con la muy complicada prueba del momento en que se ha tenido "conocimiento personal del juicio", en la que no se innova ni se dan mayores claridades.

\section{CONCLusiones}

1. Todo sistema procesal debe tener medios para corregir las situaciones en las que se producen rebeldías involuntarias, producto de la ineficacia de sus formas de comunicación. Esta necesidad se refuerza en la medida de que se agudizan las consecuencias de la rebeldía.

53 Boletín 8197-07.

${ }^{54}$ El artículo 93 PCPC autoriza al ministro de fe a determinar in situ la procedencia de una notificación por cédula en subsidio de la personal, consolidando una tendencia que ya se apreciaba en el procedimiento del trabajo (artículo 437 del Código del Trabajo) y el procedimiento de familia, artículo 23, inciso segundo, Ley 19.968 . 
2. En nuestro ordenamiento procesal civil esta función la cumple el incidente del art. $80 \mathrm{CPC}$, que permite a los litigantes rebeldes rescindir lo obrado cuando no se ha enterado de su existencia, incluso en casos en los que estos se encuentran afinados.

3. El legitimado para incoar este procedimiento no es solo el demandado, sino también terceros que no han sido llamados al juicio, debiendo haberlo sido.

4. Las hipótesis indicadas en el art. 80 son meramente ejemplares. Lo relevante a efectos de la procedencia es que el afectado no haya tenido conocimiento del juicio por un hecho que no le sea imputable, aun cuando la notificación haya sido completamente regular.

5. El que no se exija un perjuicio es lo que lleva al CPC a emplear la denominación "rescisión” y no nulidad, tal como se emplea también en el derecho español.

6. Quien promueva esta incidencia deberá acreditar no solo las circunstancias que impidieron un eficaz emplazamiento, sino también el momento en que tomó conocimiento de proceso.

7. La rescisión provocará la ineficacia de todo lo obrado, sin perjuicio de que por aplicación del principio de conservación algunos actos aislados mantengan su valor.

8. Este procedimiento en algunos casos procede de forma indistinta con el incidente de nulidad el art. 83 CPC y en otros con el de rescisión por fuerza mayor del art. 79. Cuando adquiere verdadera relevancia es una vez que hay sentencia firme y en casos en los que no hay defectos procesales.

9. Las modificaciones al incidente que se proponen en el PCPC son un retroceso en relación con lo actual, pues lo restringe aún más, menospreciando su importancia.

\section{BIBLIOGRAFÍA}

Bianchi, Humberto, 1949: "El artículo 80 del Código de Procedimiento Civil", en Revista de Derecho (Universidad de Concepción), Nº 68, año XVII, pp. 177-196.

Bordalí, Andrés; Cortez, Gonzalo; y Palomo, Diego, 2016: Proceso Civil: Los recursos y otros medios de impugación, Santiago, Legal Publishing.

Bresnan, Peter H. y Cornelio, James P., 1981: "Relief fron Default Judgments Under Rule 60(b)- A Study of Federal Case Law”, en Fordham Law Review, vol. 49, Nº 6, pp. 956-1.011.

Broceño, María del Carmen, 2014: El proceso declarativo de revisión, tesis doctoral, Universidad de Murcia.

Carlos, Eduardo, 1975: "Observaciones sobre el denominado recurso de rescisión instituido en el proceso contumacial", en Boletín Mexicano de Derecho Comparado, Nueva Serie, Año VIII, $\mathrm{N}^{\circ}$ 22-23, pp.143-152.

CARrasco, Jaime, 2010: La rebeldía en los procesos civil y laboral, Santiago: Legal Publishing.

CARrasco, Jaime, 2015: "Razones jurídicas que justifican la improcedencia de aplicar el estatuto de la nulidad de derecho público contra los actos jurisdiccionales", en Revista Chilena de Derecho, vol. 42, No 2, pp. 671-700.

Colombo, Juan, 1997: Los actos procesales, tomo II, Santiago: Editorial Jurídica de Chile.

D’ Adamo, Daniela, 2012: Contributo allo studio della contumacia nel processo civile, Milano: Giuffrè. 
FigueroA, Juan Agustín y Morgado, Erika, 2013: Procedimientos civiles e incidentes, Santiago: Legal Publishing.

Furquet, Noelia, 2005: Las comunicaciones procesales, Barcelona: Atelier.

Gorigortía, Felipe, 2013: "Irregularidad, invalidez e ineficacia en el contexto de la nulidad procesal”, en Revista de Derecho de la Universidad Católica del Norte, Vol.20 Nº.1, pp. 129-154.

Hess, Burkhard y Jaurenig, Othmar: 2015: Manual de Derecho procesal civil, Madrid: Marcial Pons.

Hoyos, Francisco, 2001: Temas fundamentales de Derecho Procesal, Santiago: LexisNexis.

Orellana, Fernando y Pérez Ragone, Álvaro, 2007: "Radiografía de la rebeldía en el proceso civil: Tópicos hacia una adecuada regulación en la nueva justicia civil”, en Ius et Praxis, año 13, $\mathrm{N}^{\circ} 2$, pp. 13-44.

Otero, Miguel, 2009: La nulidad procesal civil, penal y de derecho público, Santiago: Editorial Jurídica de Chile.

Pereira, Hugo, 2004: La cosa juzgada en el proceso civil, segunda edición actualizada, Santiago: LexisNexis.

Pérez, Álvaro y Núñez, Raúl, 2015: Manual de derecho procesal civil. Los medios de impugnación, Santiago: Thomson Reuters.

Ramos Méndez, Francisco, 2008: Enjuiciamiento civil, tomo II, Barcelona: Atelier.

Romero, Alejandro, 2004: La cosa juzgada en el proceso civil chileno, Santiago: Editorial Jurídica de Chile.

Romero, Alejandro, 2017: Curso de Derecho Procesal Civil, tomo IV, Santiago: Thomson Reuters.

SALAS, Julio, 2000: Los incidentes y en especial el de nulidad en el proceso civil, penal y laboral, séptima edición actualizada, Santiago: Editorial Jurídica de Chile.

SANTA Cruz, Víctor, 1936: Ensayo sobre la teoría de las nulidades procesales en el Código de Procedimiento Civil chileno, Imprenta Chile, Santiago.

TAvolari, Raúl, 2004: "La nulidad procesal en el derecho actual”, en El proceso en acción, Santiago: Libromar, pp. 243-278.

Urrutia, Manuel, 1928: Nulidades procesales, Santiago: Imprenta y encuadernación V. Silva.

Yelamos, Estela, 2006: Nulidad procesal y comunicaciones judiciales fallidas, Barcelona: Atelier.

Normas jurídicas citadas

Federal Rules of Civil Procedure (Estados Unidos de Norteamérica) de 2007.

LEY de Enjuiciamiento Civil (España) de 1855.

LEY de Enjuiciamiento Civil (España) de 1881.

ZIVILPROCESSORDNUNG (Alemania) de 1887.

Código de Procedimiento Civil de 1902.

Codice de Procedura Civile (Italia) de 1940

Código Orgánico de Tribunales de 1943.

Código Tributario de 1974

LEY 18.101, que fija normas especiales sobre arrendamiento de predios urbanos, de 1981.

DFL 707, que fija texto refundido, coordinado y sistematizado de la ley sobre cuentas corrientes bancarias y cheques, de 1982 .

Código del Trabajo de 1987.

LEY 19.968, crea los tribunales de familia, 2004.

Proyecto de ley que establece el nuevo Código Procesal Civil, Boletín 8197-07, de 2012. 


\section{Jurisprudencia citada}

Corte Suprema, sentencia de 23 de mayo 2003, rol No 4.443-2002.

Corte de Apelaciones Valdivia, sentencia de 29 de enero de 2004, rol 14.899-2003.

Corte de Apelaciones de Chillán, sentencia de 11 de mayo de 2004, rol № 27.332-2003.

Corte de Apelaciones de Concepción, sentencia de 9 de julio de 2004, rol No 3.207-2003.

Corte Suprema, sentencia de 2 de mayo de 2006, rol 3.284-2004.

Corte Suprema, sentencia de 3 de julio de 2007, rol No 1.111-1997.

Corte de Apelaciones de Santiago, sentencia de 15 de mayo de 2011, rol 5.486-2011.

Corte de Apelaciones de Chillán, sentencia de 6 de agosto de 2013, rol No 260-2013.

Corte Suprema, sentencia de 2 de diciembre de 2013, rol 4.763-2013.

Corte de Apelaciones de San Miguel, sentencia de 24 de julio de 2014, rol No 115-2014.

Corte de Apelaciones de Santiago, sentencia de 18 de agosto de 2014, rol No 8.664-2016.

Corte de Apelaciones de Santiago, sentencia de 3 de agosto de 2016, rol No 5.872-2016.

Corte Suprema, sentencia de 27 de octubre de 2016, rol 28.606-2016.

Corte Suprema, sentencia de 16 de enero de 2017, rol 820-2015.

Conte de Apelaciones de Talca, sentencia de 13 de julio de 2018, rol 978-2018.

Corte de Apelaciones de Antofagasta, sentencia de 6 de junio de 2019, rol 407-2019.

CORTE Suprema, sentencia de 17 de octubre de 2019, rol 12.139-2019.

Corte Suprema, sentencia de 24 de octubre de 2019, rol 24.165-2019.

Corte de Apelaciones de Rancagua, sentencia de 15 de abril 2020, rol 376-2020.

Corte Suprema, sentencia de 30 de abril de 2020, rol 29.322-2019. 